\title{
Endothelin 1 concentrations in infants with meconium stained amniotic fluid
}

\author{
S Yigit, G Tekinalp, O Oran, M Yurdakok, D Aliefendioglu, A Gurgey
}

Arch Dis Child Fetal Neonatal Ed 2002;87:F212-F213

Plasma endothelin 1 concentrations were determined in infants with meconium stained amniotic fluid. Plasma endothelin 1 concentration in the study group 15.23 $\mathrm{pg} / \mathrm{ml}$ ) was statistically higher than that in the control group (1.12 pg/ml). Cord blood $\mathrm{pH}$ and base excess values were significantly lower in infants with meconium stained amniotic fluid when compared with the control group. There was no correlation between endothelin 1 concentrations and $\mathrm{pH}$ or base excess values. Results suggest that meconium passage is not a physiological event, even if meconium stained infants appear to be clinically healthy.

M econium is a viscous green liquid that consists of gastrointestinal secretions, bile, bile acids, mucus, pancreatic juice, cellular debris, swallowed vernix caseosa, lanugo, and blood; 10-15\% of all babies will pass the substance prior to birth. ${ }^{1}$ Although some studies have shown that the majority of fetuses passing meconium are not in distress, ${ }^{2}$ passage of meconium has been often used as a marker of ante- or intrapartum asphyxia. ${ }^{3}$ Within hours of exposure to meconium, there is a profound pulmonary inflammatory response. ${ }^{4}$ Increased concentrations of inflammatory cytokines and endothelin 1 are produced as a result of meconium injury. ${ }^{45}$ These vasoactive mediators play a role in the pulmonary artery vasoconstriction of persistent pulmonary hypertension, which is frequently associated with meconium aspiration syndrome (MAS). ${ }^{5}$ Wiswell ${ }^{3}$ indicated the need to delineate the potential role of meconium itself in the direct production of end organ damage rather than this damage being the secondary effect of hypoxaemia as a result of lung disease.

The objective of this study was to determine plasma endothelin 1 concentrations in infants with meconium stained amniotic fluid (MSAF).

\section{MATERIALS AND METHODS}

Infants with MSAF born in Hacettepe University Hospital were eligible for the study. The control group was chosen from healthy term infants without MSAF. Infants with major congenital anomalies, congenital heart disease, sepsis, or metabolic diseases, and infants of mothers with preeclampsia, diabetes, or early membrane rupture were excluded. Written informed consent was obtained from the mothers.

At delivery, the umbilical cord was clamped and arterial blood ( $1 \mathrm{ml}$ ) was collected for the automated determination of blood gases. MAS is diagnosed as respiratory distress in an infant whose symptoms cannot be explained other than being a result of birth through MSAF. ${ }^{6}$ The data collected for each neonate included gestational age, birth weight, maternal age, sex, delivery route, consistency of meconium, and Apgar scores. Peripheral venous blood was collected from the infants within six hours of life in prechilled tubes containing EDTA; plasma was stored at $-20^{\circ} \mathrm{C}$ until the endothelin assay. The concentration of endothelin 1 was measured with the R\&D ELISA system.

Approval for the study was obtained from the Clinical Research Ethical Committee of Hacettepe University.

Data were expressed as mean (SD) and evaluated for significance with Student's $t$ test, ANOVA, and $\chi^{2}$ analysis. The endothelin 1 values were not normally distributed; therefore, they were log transformed before the statistical analysis.

\section{RESULTS}

There were 60 infants in the study group and 26 controls. There was no statistical difference in gestational age, birth weight, delivery route, or gender between the study and control groups (table 1). The study group had a younger mean maternal age. Apgar scores and cord blood gases were statistically different between the groups (fig 1). Plasma endothelin l concentration in the study group was statistically higher than that in the control group (fig 2).

No correlation was found between endothelin 1 concentrations and $\mathrm{pH}$ or base excess values. There was a negative correlation between $\mathrm{pH}$ and base excess values $(r=-0.691$, $\mathrm{p}=0.01)$. Seven of the 60 cases were diagnosed as meconium aspiration syndrome. No statistically significant difference was found in plasma endothelin I concentrations between the MAS group and the infants with MSAF.

\section{DISCUSSION}

The role of endothelin 1 in the pathogenesis of pulmonary hypertension of the newborn is well documented. ${ }^{5}$ In this study we showed that endothelin 1 concentrations are increased in infants with MSAF. To our knowledge, this is the first study investigating endothelin 1 concentrations in meconium stained infants without MAS. Although 53 of 60 patients had no respiratory symptoms for diagnosis of MAS, their endothelin 1 concentrations were increased compared with the control group.

A multicentre study showed that a high rate of respiratory disorders other than MAS occurred among infants born through $\mathrm{MSAF}^{7}$ These findings indicate that the presence of meconium is likely to produce certain systemic effects other than pulmonary damage. In accordance with these findings, we showed that meconium stained infants have raised endothelin 1 concentrations, indicating that either the presence of meconium leads to systemic effects or that events such as hypoxia lead to meconium passage. Hashiguchi et al showed a relation between fetal hypoxia and fetal endothelin 1 concentrations. ${ }^{8}$ They showed that the mean plasma concentration of endothelin 1 in umbilical venous blood with

Abbreviations: MAS, meconium aspiration syndrome; MSAF, meconium stained amniotic fluid 
Table 1 Characteristics of study and control groups

\begin{tabular}{|c|c|c|}
\hline & Meconium $(n=60)$ & Controls $(n=26)$ \\
\hline Gestational age (wk) & 39.1 (1.1) [37 to 41$]$ & 38.3 (1.0) [37 to 41$]$ \\
\hline Birth weight (g) & 3337 (419) [2350 to 4400 ] & $3358(368)$ [2750 to 4000$]$ \\
\hline Maternal age (y) & $27.6(5)^{*}[17$ to 38$]$ & $31.2(4) *[24$ to 41$]$ \\
\hline $\mathrm{pH}$ & $7.24(0.08) *[7.06$ to 7.40$]$ & $7.31(0.04) *[7.2$ to 7.43$]$ \\
\hline Base excess (mEq/l) & $-5.98(3.3)^{* * *}[-13.40$ to 0$]$ & $-2.59(2.1)^{* * *}[-0.20$ to -7.9$]$ \\
\hline Apgar score (5th minute) & $9.16(1.1)^{*}[5$ to 10$]$ & $9.62(0.5)^{*}[8$ to 10$]$ \\
\hline Endothelin 1 (pg/ml) & $5.23(9.2)^{* * *}[0.052$ to 45.07$]$ & $1.12(0.89)^{* * *}[0.10$ to 3.19$]$ \\
\hline
\end{tabular}

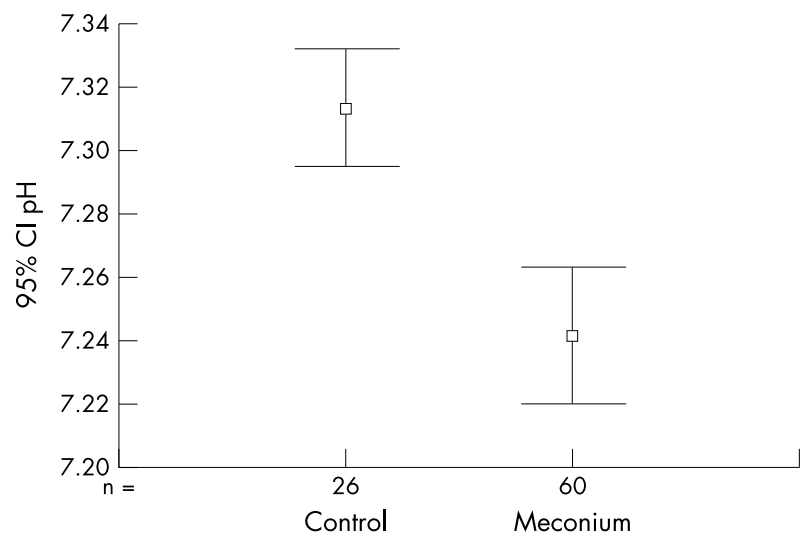

Figure 1 Mean cord blood $\mathrm{pH}$ in control and meconium groups.

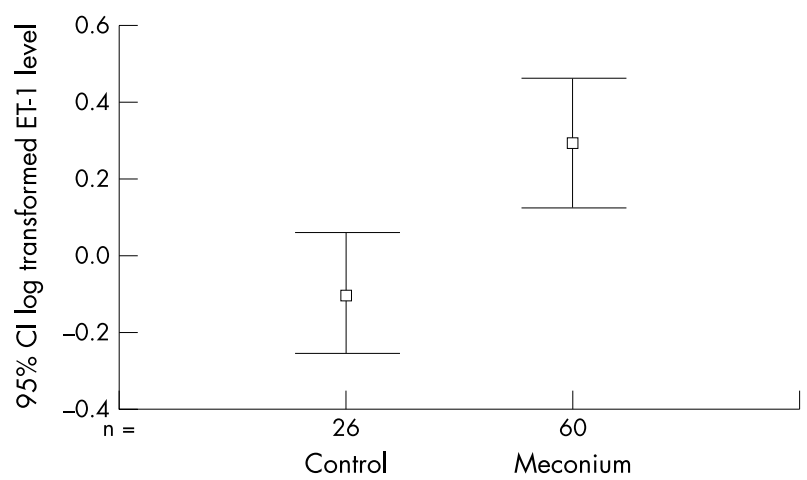

Figure 2 Mean plasma log transformed endothelin 1 (ET-1) in control and meconium groups.

a pH below 7.30 was significantly higher than that in samples with a pH above 7.30. This finding is in accordance with our results; cord blood pH was below 7.30 in most of the patients with MSAF, although endothelin 1 concentrations in cord blood were not measured in our study. It seems that the presence of meconium is associated with a mild degree of hypoxia without clinical symptoms.

There was no significant difference in endothelin 1 concentrations between infants with MAS and meconium stained infants without MAS. This may be a result of the small number of infants with MAS in the study.
There are no data suggesting a younger maternal age in meconium stained amniotic fluid, so we considered this a coincidence.

In conclusion, we have shown that endothelin 1 concentration was higher in infants with MSAF. These results suggest that meconium passage is not a physiological event, even if meconium stained infants appear to be clinically healthy. However, if there is an increase in endothelin l concentrations, it is unclear whether meconium passage is the cause of the increase in endothelin 1 concentrations or vice versa.

\section{ACKNOWLEDGEMENT}

This study was supported by the Scientific and Technical Research Council of Turkey (TUBITAK).

(1)

Authors' affiliations

S Yigit, G Tekinalp, O Oran, M Yurdakok, Hacettepe University Hospital, Department of Pediatrics, Division of Neonatology

D Aliefendioglu, Social Security Hospital, Ankara

A Gurgey, Hacettepe University Hospital, Department of Pediatrics, Division of Haematology

Correspondence to: Dr S Yigit, Ziraat Mühendisleri Sitesi 3/21 Çankaya 06550, Ankara, Turkey; Suleyigit@turk.net

Accepted 17 May 2002

\section{REFERENCES}

1 Wiswell TE, Tuggle JM, Turner BS. Meconium aspiration syndrome. Have we made a difference? Pediatrics 1990;85:715-21.

2 Mitchell J, Schulman $\mathrm{H}$, Fleischer $\mathrm{A}$, et al. Meconium aspiration and fetal acidosis. Obstet Gynecol 1985;65:352-5.

3 Wiswell TE. Meconium staining and the meconium aspiration syndrome. Pediatr Clin North Am 1993;40:955-81.

4 Davey AM, Becker JD, Davis JM. Meconium aspiration syndrome: physiological and inflammatory changes in a newborn piglet model. Pediatr Pulmonol 1993;16:101-8.

5 Endo A, Ayusawa M, Minato $M$, et al. Endogenous nitric oxide and endothelin-1 in persistent pulmonary hypertension of the newborn. Eur J Pediatr 2001;160:217-22.

6 Cleary GM, Wiswell TE. Meconium stained amniotic fluid and the meconium aspiration syndrome. Pediatr Clin North Am 1998;45:51 1-29.

7 Wiswell TE, Gannon CM, Jacob J, et al. Delivery room management of the apparently vigorous meconium stained neonate: results of the multicenter, international collaborative trial. Pediatrics 2000;105:1-7.

8 Hashiguchi K, Takagi K, Nakabayashi M, et al. Relationship between fetal hypoxia and endothelin-1 in fetal circulation. J Cardiovasc Pharmacol 1991;17(suppl 7):S509-10. 